\title{
Implementation of a Portable E-Nose System to Identify the Water Stresses of Khasi Mandarin Orange Plants
}

\author{
Rajdeep Choudhury ${ }^{1}$, Sudipta Hazarika ${ }^{2}$, Utpal Sarma ${ }^{3}$ \\ 1,2 Ph.D., Students, Department of Instrumentation and USIC, Gauhati University, Assam, India. \\ ${ }^{3}$ Professor, Department of Instrumentation and USIC, Gauhati University, Assam, India.
}

ORCID: 0000-0002-6116-6085 (Rajdeep)

\begin{abstract}
Plants usually produce a wide range of volatile organic compounds (VOCs) in its various tissues to communicate with each other or with other organisms. When a plant is exposed to any kind of biotic or abiotic stresses, its VOC profile altered qualitatively and quantitatively. This paper addresses the development of customised E-Nose system and its application to identify Khasi Mandarin orange plants' water stress levels by sensing the emitted VOCs. The system was developed using nine MOS gas sensors which sense the VOCs emitted by the plants' leaves and the results were correlated with the three induced water stress levels. The dimensions of the data were initially reduced with the help of a dimensionality reduction tool called Linear Discriminant Analysis (LDA) and the dimensionally reduced data were classified using support vector classifier (SVC). The performance of the system was evaluated in terms of Accuracy, Precision and Recall scores of the classifier. The developed E-Nose is able to discriminate the plants with different stress levels, which will be helpful to manage irrigation scheduling.
\end{abstract}

Keywords: Volatile organic compounds, Electronic nose, Khasi Mandarin orange, Drip irrigation, Machine learning, water stress.

\section{INTRODUCTION}

Water is a crucial component for every form of life to maintain a healthy ecosystem. It is an imperative component to agriculture, since quality seeds unable to reach their maximum potential in the absence of the optimum level of water despite having sufficient fertilizers[1]. A plant is considered to be as water-stressed if it is unable to uptake sufficient water from the ground due to water scarcity. Drought/water stress poses a frequent and serious threat to crop health which eventually causes a significant loss in crop production. The international commission on irrigation and drainage highlighted that almost $40 \%$ of world's population is suffered the problem of periodic droughts, which affect the arid and semi-arid countries in Middle Asia and north of Africa, China, parts of India, Maxico, Astralia etc[2]. In [3] G. Giaouris et al. found that nearly onethird of worlds potential arable land is suffering from different levels of water stresses. Mortazavian et al. found that due to the lack of sufficient water the growth and development process of a plant is affected adversely[4]. The damage depends on the plant's developmental stage at which the drought occurs along with the severity of the drought[5]. Kiremit et al. observed that irrigation rate also plays an important role in case of plants health and growth. They noticed a significant alteration in the height, stem length, leaf length, stem diameter, fresh weight of leaf and stem and dry weight of Leek when changing the irrigation rate[6].

Plants response towards stresses, biotic and abiotic, is very much complicated. Significant research is going on to understand the different metabolic pathways which trigger plants' defence mechanism. Plants usually reprogram their gene expression profile along with the metabolic contents. This paper emphasizes on the study of plants' response to water stress, generates due to unavailability of water in the soil, which implies the change in their biochemistry as well as the change in root structures to retain and absorb maximum possible water for important metabolic functioning. Plants produce and accumulate solutes such as amino acid, polyols, and sugars to decrease the cell osmotic potential which encourages the retention of the water within itself. In addition, it produces Abscissic Acid (ABA), a stress hormone, which effects the growth pattern and stress tolerance[7]. ABA also involve in the transpiration by controlling the guard cells of the stomatal opening [8], [9]. Emission of secondary metabolites also acts as a defence mechanism to protect the plant itself as well as alerting neighbouring plants. In [7], [10] it is amply described that biotic (pathogen, aphids, herbivory) and abiotic stresses (environmental origin) causes an alteration in secondary metabolites, emitted as a VOCs. These emitted metabolites serve as plant to plant, pathogen to host, and plant to vector communications besides defence mechanisms. According to Dorokhov et. al. methanol emission due to leaf wounding primes the distant leaves of the same tree as well as neighbouring trees providing anti-bacterial resistance[11].

The study of plants' VOC emission profile using analytical instruments or electronic nose (e-nose) can be used as a diagnostic tool for detecting plants' various biotic and abiotic stresses. R. C. Ebel et al. studied the VOC emission pattern of apple plant using GC-MS for different water stress levels and identified twenty-nine VOCs among which emission rates of hexanal, (E)-2-hexenal, (E)-2-hexen-1-ol, 1-hexanol, hexyl acetate, and (E)-2-hexenyl acetate were unregulated in severely stressed plant[12]. In [13] it is described that the VOC profile of apple plants changed due to environmental factors like temperature, relative humidity and rainfall. U. Hansen et al. studied the VOC profile of citrus sinensis and found that the emission of terpenoid is changed due to the stress effect[14]. 


\section{RELATED WORK}

Different techniques have been used to detect plants' water stress whereas various research still going on in this aspect. $M$. J. Savage et al. used the density method technique to detect plants' leaf water potential[15]. In [16], [17] pressure chamber technique was used to find the leaf water potential where a controlled pressure is applied and increased gradually to the leaf of a plant in a chamber until the leaf secrets sap from its shoot. Savage et. al. used Scholander's pressure Chamber and thermocouple psychrometry to measure the leaf water potential of citrus jambhiri [15]. In [18] Nadler et al. used time-domain reflectometry to study the stem water content and stem electrical conductivity which is generated due to induced water stresses in four different species of trees for a certain period. Whereas Arthur I. Zygielbaum et. al used reflectance spectroscopy to study the optical properties of stressed and nonstressed maize leaves[19]. Zheng et al. found that there is a relationship between plants' water stress and its physiological electrical properties. He used the four-electrode methods in corn leaves for the experiments[20]. Infrared short waves were used by Kim et al. to take the hyper-spectral images of leaves, which was used as an indicator of plants' health status[21]. Similarly, Maria A. Moreno-Pizani et al. used a hand-held infrared thermometer to measure the canopy temperature to detect crop water stress index of a medicinal plant (Baccharis crispa Spreng.)for different irrigation levels[22]. The application of e-nose in fruits' quality inspection and disease detection is profuse[23]. Commercial E-Nose, Alfa Mos Fox 3000 , system is used in [24] to identify the water stresses present in the plants by sensing the VOCs emitted by plants' leaves.

\section{METHOD}

In this work, an E-Nose system is developed to detect Khasi Mandarin orange plants' water stress levels by sensing the VOC profiles of the plants. Ten plants were considered for the experiment and planted them in plastic pots inside a greenhouse. Initially, the plants were irrigated with the optimum amount of water that is required by the plant to survive in a non-water stressed condition. Then withhold water flow for the next 8 days to induce different levels of water stresses. The stress induction was confirmed by measuring leaf Relative Water Content (RWC). Leaf samples were collected from the plants on three different time intervals-(a). Before withholding water supply, (b). On the $4^{\text {th }}$ day after withholding water supply and (c). On the $8^{\text {th }}$ day after withholding water supply. The collected samples were tested using the developed E-Nose system and analyzed using machine learning algorithm.

The entire work is divided into two parts, hardware development and software implementation. Hardware development section describes the development of a customised E-Nose system and its application to acquire VOCs emitted by the leaves of Khasi Mandarin orange plants. Whereas the software implementation section describes the analyses process of the acquired E-Nose data. The sample preparation, system development, experimental methods and data analyses process are discussed below.

\section{III.I Sample preparation}

The experiment performed at Gauhati University, Assam, India. Ten healthy mandarin orange saplings, collected from Citrus Research Station, Tinsukia, Assam and planted in pots $(30 \mathrm{~cm}$ diameter top, $20 \mathrm{~cm}$ diameter base and $28 \mathrm{~cm}$ height) inside a greenhouse. The pots are filled with the same quality soil. The inner environment of the greenhouse, such as temperature, humidity, and light exposure is maintained constant throughout the entire experimental tenure. Saplings were kept at that controlled environment 30 days before starting the experiments so that to protect the plants from any kind of unwanted stresses. The amount of water used to irrigate the plants are controlled with the help of a drip irrigation system as shown in Fig.1.

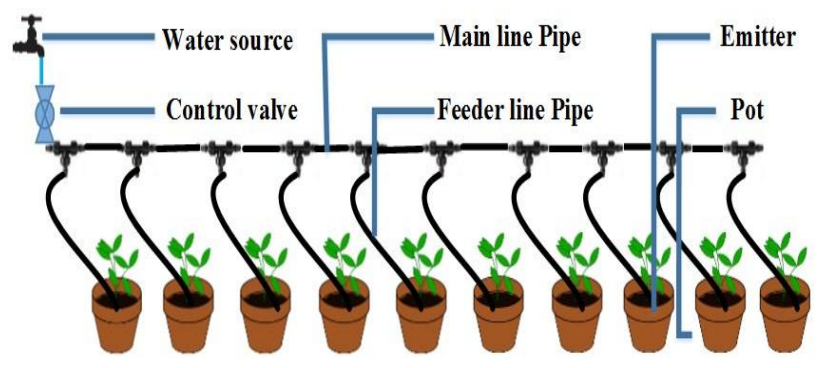

Fig.1. Drip irrigation setup

Initially, the optimum amount of water required to be irrigated to a plant so that it can live in a non-stressed condition is calculated by using the value of crop evapotranspiration $\left(E T_{c}\right)$. Reference evapotranspiration $\left(E T_{0}\right)$ is calculated by Penman Monteith method [25] where important parameters like temperature, humidity etc. are taken from the climatic data.

The equation to find out $E T_{0}$ is shown equation 1 .

$$
E T_{0}=\frac{0.408 \Delta\left(\mathrm{R}_{\mathrm{n}}-G\right)+\gamma \frac{900}{T+273} u_{2}\left(e_{s}-e_{a}\right)}{\dot{\Delta}+\gamma\left(1+0.34 u_{2}\right)}
$$

Where, $E T_{0}=$ reference evapotranspiration $\left[\mathrm{mm} \mathrm{day}^{-1}\right], \mathrm{G}=$ soil heat flux density $\left[\mathrm{MJ} \mathrm{m} \mathrm{m}^{-2} \mathrm{day}^{-1}\right], \mathrm{R}_{\mathrm{n}}=$ net radiation at the crop surface $\left[\mathrm{MJ} \mathrm{m}^{-2}\right.$ day $\left.^{-1}\right], \mathrm{U}_{2}=$ wind speed at $2 \mathrm{~m}$ height $\left[\mathrm{ms}^{-1}\right], \mathrm{T}=$ mean daily air temperature at $2 \mathrm{~m}$ height $\left[{ }^{0} \mathrm{C}\right], \mathrm{e}_{\mathrm{s}}=$ saturation vapour pressure $[\mathrm{kPa}], \mathrm{e}_{\mathrm{a}}=$ actual vapour pressure $[\mathrm{kPa}],\left(\mathrm{e}_{\mathrm{s}^{-}}\right.$ $\mathrm{e}_{\mathrm{a})}=$ saturation vapour pressure deficit $[\mathrm{kPa}], \Delta=$ slope vapour pressure curve $\left[\mathrm{kPa}^{0} \mathrm{C}^{-1}\right], \gamma=$ psychrometric constant $\left[\mathrm{kPa}{ }^{0} \mathrm{C}^{-}\right.$ $\left.{ }^{1}\right]$.

The relationship between the $E T_{c}$ and $E T_{0}$ is shown in equation 2 .

$$
E T_{c}=K_{c} \times E T_{0}
$$

Where, $\mathrm{K}_{\mathrm{C}}$ is the crop coefficient.

$E T_{0}$ was calculated using a software, CROPWAT 8.0, which works based on the Penman Monteith method. The ambient temperature inside the greenhouse was set at $20^{\circ} \mathrm{C}$, with a hysteresis of $1^{\circ} \mathrm{C}$ and relative humidity at $40 \%$. The saplings were exposed to light for 8 hours per day. Put these values in the software, CROPWAT 8.0, which gave the value of $E T_{0}$. The value of $E T_{c}$ was calculated from equation 2 and was found 
to be $2.3035 \mathrm{~mm} /$ day. Since the area to be irrigated for each plant is $0.070695 \mathrm{~m}^{2}$ hence the estimated optimum amount of water $\left(\mathrm{W}_{0}\right)$ required to supply to each plant was found out to be $162.85 \mathrm{ml} /$ day.

A month after planting the plants inside the greenhouse, leaf samples from each plant are collected for E-Nose and RWC measurement experiments. The water supply to the plants are then withheld for the next eight days and samples were collected from the plants on $4^{\text {th }}$ and $8^{\text {th }}$ day to perform the experiments. The plants were then re-watered with the optimum value for next one month and repeat the whole process.

\section{III.II E-Nose system development}

An E-Nose system is a technique which can mimic the human olfaction process. It senses and identifies the gas mixture as a whole without recognizing the individual gases present in the mixture[26]. This paper addresses the use of a customised ENose system that used to sense the VOCs emitted by the leaves of Khasi Mandarin orange for different levels of water-stressed conditions. The developed system consists of three major parts: sample delivery, data acquisition and computing system. The block diagram of the system is shown in Fig.2.

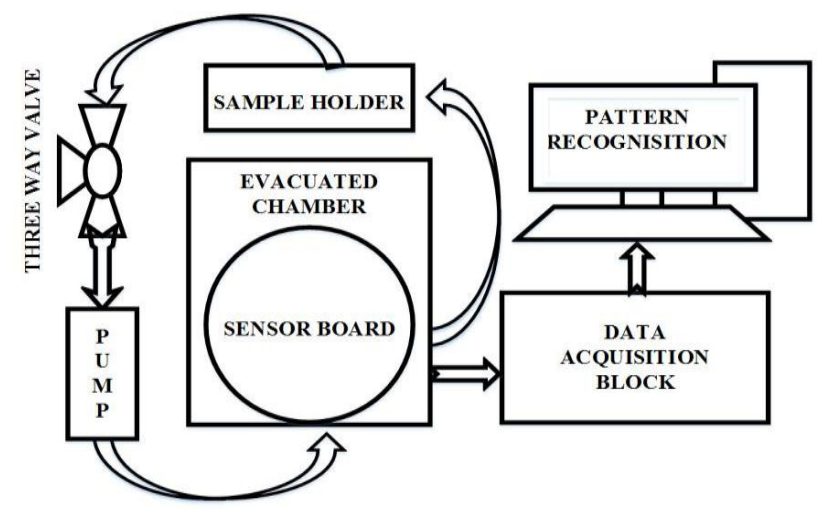

The sample delivery system consists of two evacuated chambers namely sample holder and sensor housing chamber which are connected with the help of a network of pipe and a vacuum pump as shown in the figure. The data acquisition part comprises of an array of gas sensors followed by a DAS. The sensors sense the odor of the test conditions and converted them to electrical signals. The DAS then acquired these electrical signals with the help of its input channels and recorded for analyses.

The sensor array of the developed system contains nine MOS gas sensors. The sensors are chosen based on a pre-test which was performed to detect water stress of Khasi Mandarin orange plant using a commercial E-Nose system Alpha Fox 3000 [24]. The names of the sensors are shown in Table 1, along with their target gases. The sensor array is housed inside the evacuated chamber as shown in Fig. 2. The chamber is linked with the sample holder with the help of a vacuum pump and a network of the pipe as shown in the figure. The pump is used to deliver the VOCs emitted by the samples to the sensor board whereas the three-way valve connected in between the two chambers is used to purge the chamber after completion of each test by allowing fresh air to flow inside. The picture of the developed system is shown in Fig. 3.

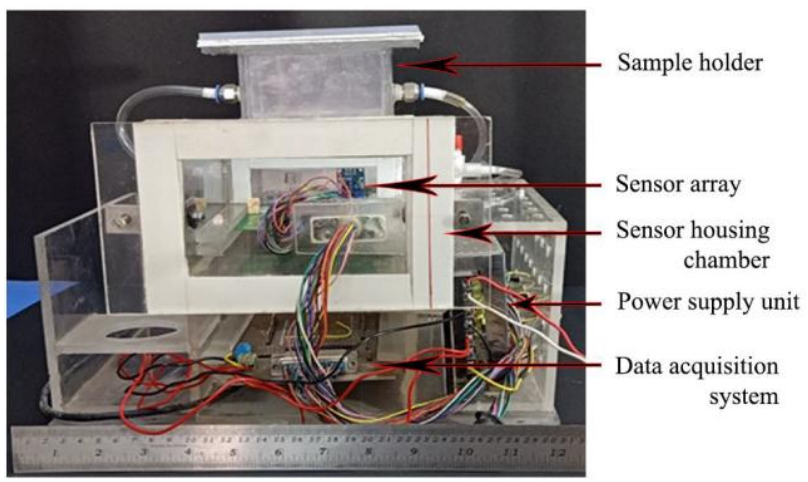

Fig. 3. The developed E-Nose system

Fig.2. Block diagram of the designed prototype

Table 1. Name of the sensors along with their target gases

\begin{tabular}{|l|l|}
\hline Sensors name & Target gases \\
\hline TGS 822 & Methane, ISO-butane, Carbon-monoxide, n-Hexane, Benzene, Ethanol \\
\hline TGS 2620 & Alcohol, solvent vapors \\
\hline TGS 5141 & Carbon monoxide \\
\hline MQ4 & Methane, CNG \\
\hline MQ3 & Alcohol, smoke, Ethanol \\
\hline MQ6 & LPG, butane \\
\hline TGS2444 & Ammonia \\
\hline TGS 2610 & Methane, Iso-butane/Propane, Ethanol \\
\hline TGS2602 & Ammonia, Toluene, Ethanol, Hydrogen Sulfide \\
\hline
\end{tabular}


International Journal of Engineering Research and Technology. ISSN 0974-3154, Volume 13, Number 10 (2020), pp. 2562-2567

(C) International Research Publication House. https://dx.doi.org/10.37624/IJERT/13.10.2020.2562-2567

\section{III.III Experimental methods}

Leaf samples (fully developed and weighing approximately 10 grams from each plant) collected from the plants are cleaned with $75 \%(\mathrm{~V} / \mathrm{V})$ ethanol to remove the traces of dirt as well as the superficial microorganisms. Samples are then kept inside the sample holder where clean dry air is used to deliver the emitted VOCs to the sensor housing chamber of the E-Nose system. Sensors' responses for the test condition are acquired by the system for five minutes at an interval of one sec. Twentyminute recovery time is given to the system between two subsequent experiments. Since the system has nine sensors (features) to record the data at an interval of one sec for 5 minutes, hence created a data matrix of the dimension $300 \times 9$ for each sample. Fig. 4 shows the responses of individual sensors for a test condition. These data acquired by the E-Nose system was further analysed with machine learning algorithms as described in the result and discussion section.

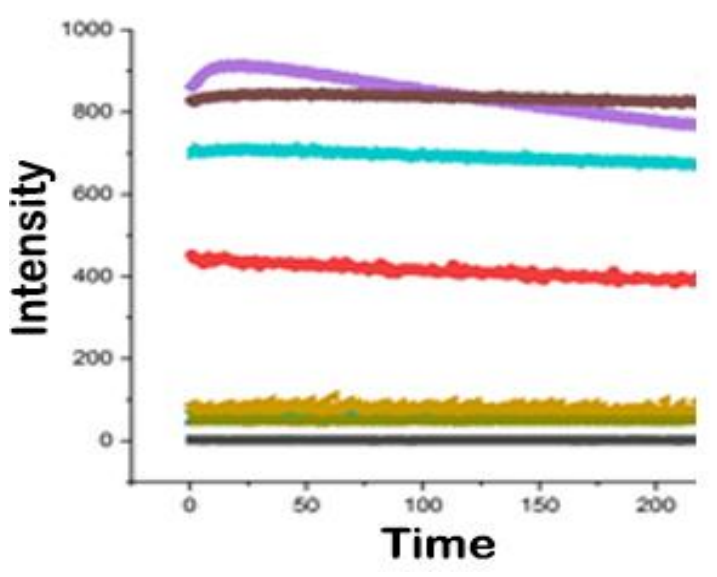

Fig. 4. Sensor responses of the E-Nose system

\section{RESULTS AND DISCUSSIONS}

The E-Nose tests were performed to observe the effect of water stress in Mandarin orange plants. Three classes of data were generated after the completion of the tests based on the water stress values of the sample plants. The stresses were induced in the plants by withholding water supply and the samples were collected on the $0^{\text {th }}, 4^{\text {th }}$ and $8^{\text {th }}$ day. Sample plants were then rewatered with the optimum amount of water for the next month. Then similar kind of tests was repeated by withholding supplied water like before. Hence two sets of data were generated after the completion of the entire experiment where each set consists of three classes of data.

The Relative Water Content (RWC) of the leaves of the plants were simultaneously measured to confirm the induction of stresses in the plants. RWC measurement is a process to evaluate leaf water status in the cellular level [27] which can further used to evaluate the overall water status of the plant. Table II shows the RWC values for three different categories of plants for the $1^{\text {st }}$ set of experiment. From the table, it is seen that RWC value decreased when the water stress level increase.
Table II. RWC values for the plant at different time intervals

\begin{tabular}{|c|c|c|c|}
\hline \multirow{2}{*}{$\begin{array}{l}\text { Sample } \\
\text { names }\end{array}$} & \multicolumn{3}{|c|}{ RWC } \\
\cline { 2 - 4 } & $\mathbf{0}^{\text {th }} \mathbf{d a y}$ & $\mathbf{4}^{\text {th }}$ day & $\mathbf{8}^{\text {th }}$ day \\
\hline Sample 1 & $92 \%$ & $72 \%$ & $55 \%$ \\
\hline Sample 2 & $90 \%$ & $73 \%$ & $59 \%$ \\
\hline Sample 3 & $95 \%$ & $81 \%$ & $58 \%$ \\
\hline Sample 4 & $91 \%$ & $79 \%$ & $60 \%$ \\
\hline Sample 5 & $90 \%$ & $76 \%$ & $60 \%$ \\
\hline Sample 6 & $93 \%$ & $78 \%$ & $62 \%$ \\
\hline Sample 7 & $93 \%$ & $80 \%$ & $56 \%$ \\
\hline Sample 8 & $90 \%$ & $75 \%$ & $61 \%$ \\
\hline Sample 9 & $94 \%$ & $80 \%$ & $61 \%$ \\
\hline Sample 10 & $95 \%$ & $74 \%$ & $57 \%$ \\
\hline
\end{tabular}

Data that are collected from the $1^{\text {st }}$ set of E-Nose experiment are initially pre-processed (normalized) and then split into two parts namely training set and test set. Training set acquired the major portion, $80 \%$, of the data set whereas the test set is comprised of the remaining $20 \%$. The training set is used to train the classifier model whereas the trained model is tested on the test set data to evaluate its performance. The accuracy, precision and recall scores are used to describe the performance of the classifier models

Since the data are multidimensional (9), hence the dimensions of the data set are reduced before the classification using a dimensionality reduction tool, Linear Discriminant Analysis (LDA). The new and dimensionally reduced data set is then fitted with the classification algorithm, Support Vector Classifier (SVC). The performance scores viz. accuracy, precision and recall are shown in Table. III and the decision boundaries set by the classifier are shown in Fig. 5. Similarly Fig. 6 shows the decision boundaries set by the classifier for the second set of data when classified using the same classifier whereas the accuracy, precision and recall scores are shown in Table IV. From these classification plots and the performance scores of the models, shown in Table III and IV, it is clear that the SVM classifier can classify the samples based on their stress levels with $100 \%$ accuracy.

\begin{tabular}{|c|c|c|}
\hline \multicolumn{3}{|c|}{$\begin{array}{l}\text { Table III. Performance scores of the } \\
\text { model for } 1^{\text {st }} \text { set of experiment }\end{array}$} \\
\hline \multicolumn{3}{|c|}{ SVM } \\
\hline Accuracy & Precision & Recall \\
\hline 100 & 100 & 100 \\
\hline
\end{tabular}



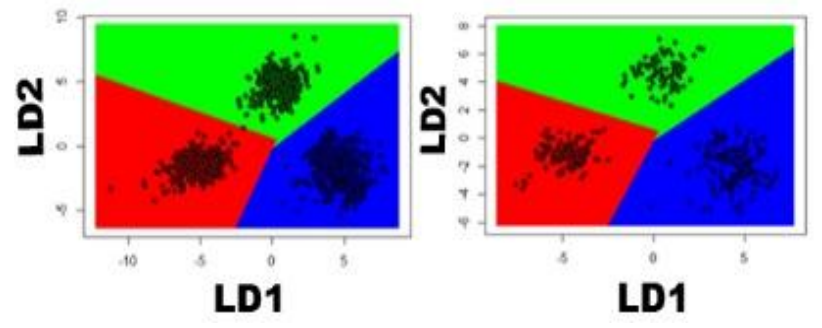

Fig.5. LDA training and test set with SVM classifier

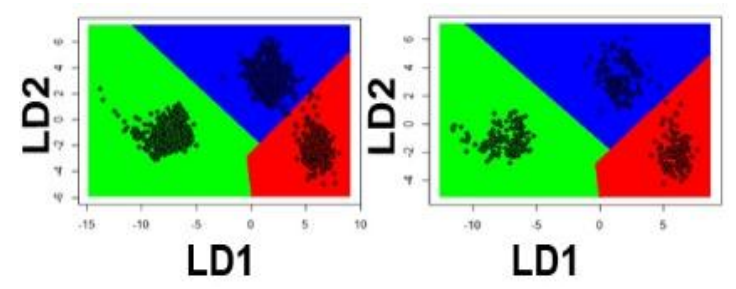

Fig.6. LDA training and test set with SVM classifier

Table IV. Table III: Performance scores of the model for $2^{\text {nd }}$ set of experiment

\begin{tabular}{|l|l|l|}
\hline \multicolumn{3}{|c|}{ SVM } \\
\hline Accuracy & Precision & Recall \\
\hline 100 & 100 & 100 \\
\hline
\end{tabular}

\section{CONCLUSION}

This study reveals the capability of a developed E-Nose system along with the appropriate machine learning algorithm to classify different levels of water-stressed plants by sensing the VOCs emitted by the leaves of the plants. For experimental purpose, ten Khasi Mandarin orange plants were planted inside a greenhouse where three different levels of water stresses were induced in the plants by withholding water supply for a few days. The stress induction was confirmed by measuring the leaf RWC values. Leaves were collected from the sample plants at three different time intervals (0th, 4th and 8th day) and tested with the developed E-Nose system. The dimensionality reduction tool LDA and the classification algorithm SVM are used to analyse the acquired data. The analyses results confirm that the algorithm can differentiate the samples based on their stress levels. Hence, it can be concluded that the developed ENose together with a suitable machine learning can identify the water stress levels of Khasi Mandarin orange plant by sensing the VOCs emitted by the leaves of the plant. It will be a reliable instrument for the agricultural farms to detect water stress levels in the plants due to its portability, non-invasive nature, low cost, and non-necessity of skilled persons to operate.

\section{ACKNOWLEDGMENT}

The authors acknowledges the Department of Science \& Technology, Govt. of India, for providing the inspire fellowship which supported throughout the research work. The authors would also like to extend their gratitude to Prof. P. J Handique, Department of Biotechnology, Gauhati University for facilitating the research work with required infrastructure. Last but not the least the authors are thankful CEERI, Pilani for their valuable suggestions and the technical knowhow.

\section{REFERENCES}

[1] C. Brouwer and M. Heibloem, "Irrigation water management: irrigation water needs," Train. Man., vol. 3, 1986.

[2] Saeed Nairiz, "Irrigated Agriculture Development under Drought and Water Scarcity."

[3] Dr. B. S M Mahmoud, Salmonella-a dangerous foodborne pathogen. .

[4] S. M. M. Mortazavian, B. Safari, S. A. Sadat Noori, and B. Foghi, "Evaluation of Diverse Cumin (Cuminum cyminum L.) Ecotypes for Seed Yield under Normal and Water Stress Condition,” J. Agric. Sci. Technol., vol. 20, no. 2, pp. 359-372, Mar. 2018.

[5] B. Jongdee, S. Fukai, and M. Cooper, "Leaf water potential and osmotic adjustment as physiological traits to improve drought tolerance in rice," Field Crops Res., vol. 76, no. 2-3, pp. 153-163, Jul. 2002, doi: 10.1016/S0378-4290(02)00036-9.

[6] M. S. Kiremit and H. Arslan, "Response of Leek ( Allium porrum L.) to Different Irrigation Water Levels Under Rain Shelter," Commun. Soil Sci. Plant Anal., vol. 49, no. 1, pp. 99-108, Jan. 2018, doi: 10.1080/00103624.2017.1421652.

[7] J. K. Holopainen and J. Gershenzon, "Multiple stress factors and the emission of plant VOCs," Trends Plant Sci, vol. 15, no. 3, pp. 176-84, Mar. 2010, doi: 10.1016/j.tplants.2010.01.006.

[8] T. C. Hsiao, "Plant Responses to Water Stress," p. 52.

[9] Ş. Akıncı and D. M. Lösel, "Plant Water-Stress Response Mechanisms," Jan. 2012, doi: 10.5772/29578.

[10] A. Arneth and Ü. Niinemets, "Induced BVOCs: how to bug our models?," Trends Plant Sci., vol. 15, no. 3, pp. 118-125, Mar. 2010, doi: 10.1016/j.tplants.2009.12.004.

[11] Y. L. Dorokhov, T. V. Komarova, I. V. Petrunia, O. Y. Frolova, D. V. Pozdyshev, and Y. Y. Gleba, "Airborne Signals from a Wounded Leaf Facilitate Viral Spreading and Induce Antibacterial Resistance in Neighboring Plants," PLoS Pathog., vol. 8, no. 4, Apr. 2012, doi: 10.1371/journal.ppat.1002640.

[12] R. C. Ebel, J. P. Mattheis, and D. A. Buchanan, "Drought stress of apple trees alters leaf emissions of volatile compounds," Physiol. Plant., vol. 93, no. 4, pp. 709-712, 1995, doi: 10.1111/j.1399-3054.1995.tb05120.x.

[13] A. Vallat, H. Gu, and S. Dorn, "How rainfall, relative humidity and temperature influence volatile emissions from apple trees in situ," Phytochemistry, vol. 66, no. 13, pp. 1540-1550, Jul. 2005, doi: 10.1016/j.phytochem.2005.04.038. 
[14] U. Hansen and G. Seufert, "Terpenoid emission from citrus sinensis (L.) OSBECK under drought stress," Phys. Chem. Earth Part B Hydrol. Oceans Atmosphere, vol. 24, no. 6, pp. 681-687, Jan. 1999, doi: 10.1016/S14641909(99)00065-9.

[15] M. J. Savage, H. H. Wiebe, and A. Cass, "In Situ Field Measurement of Leaf Water Potential Using Thermocouple Psychrometers," Plant Physiol., vol. 73, no. 3, pp. 609-613, 1983, [Online]. Available: http://www.jstor.org/stable/4268301.

[16] J. S. Boyer, "Leaf water potentials measured with a pressure chamber," Plant Physiol., vol. 42, no. 1, pp. 133137, Jan. 1967, doi: 10.1104/pp.42.1.133.

[17] J. C. O’Toole, N. C. Turner, O. P. Namuco, M. Dingkuhn, and K. A. Gomez, "Comparison of Some Crop Water Stress Measurement Methods 1," Crop Sci., vol. 24, no. 6, pp. 1121-1128, 12/01 1984, doi: 10.2135/cropsci1984.0011183X002400060028x.

[18] A. Nadler et al., "Detecting Water Stress in Trees Using Stem Electrical Conductivity Measurements," 2008, doi: 10.2136/sssaj2007.0308.

[19] A. I. Zygielbaum, A. A. Gitelson, T. J. Arkebauer, and D. C. Rundquist, "Non-destructive detection of water stress and estimation of relative water content in maize," Geophys. Res. Lett., vol. 36, no. 12, 2009, doi: 10.1029/2009GL038906.

[20] L. Zheng, Z. Wang, H. Sun, M. Zhang, and M. Li, "Realtime Evaluation of Corn Leaf Water Content Based on the Electrical Property of Leaf," Comput Electron Agric, vol. 112, no. C, pp. 102-109, Mar. 2015, doi: 10.1016/j.compag.2014.11.007.

[21] D. Kim et al., "Highly sensitive image-derived indices of water-stressed plants using hyperspectral imaging in SWIR and histogram analysis," Sci. Rep., vol. 5, Jan. 2015, doi: 10.1038/srep15919.

[22] M. A. Moreno-Pizani, A. J. Farias-Ramirez, T. H. S. Barros, J. Zucolotto, and R. D. Coelho, "Crop Water Stress Index for a medicinal plant (Baccharis crispa Spreng.) under variable irrigation levels," Water Resour. Irrig. Manag., p. 7.

[23] S. Cui, P. Ling, H. Zhu, and H. M. Keener, "Plant Pest Detection Using an Artificial Nose System: A Review," Sensors, vol. 18, no. 2, Jan. 2018, doi: 10.3390/s18020378.

[24] R. Choudhury, S. Hazarika, and U. Sarma, "Detection of Water Stress in Khasi Mandarin Orange Plants from Volatile Organic Compound Emission Profile Implementing Electronic Nose," Int. J. Eng. Adv. Technol., vol. 9, no. 1, pp. 133-137, Oct. 2019, doi: 10.35940/ijeat.A1086.109119.

[25] R. G. Allen, L. S. Pereira, D. Raes, and M. Smith, “Crop evapotranspiration - Guidelines for computing crop water requirements - FAO Irrigation and drainage paper 56," $\mathrm{p}$. 15.

[26] A. Wilson, "Diverse Applications of Electronic-Nose Technologies in Agriculture and Forestry," Sensors, vol. 13, no. 2, pp. 2295-2348, Feb. 2013, doi:
$10.3390 / \mathrm{s} 130202295$.

[27] M. R. Schlemmer, D. D. Francis, J. F. Shanahan, and J. S. Schepers, "Remotely Measuring Chlorophyll Content in Corn Leaves with Differing Nitrogen Levels and Relative Water Content," Agron. J., vol. 97, no. 1, p. 106, 2005, doi: 10.2134/agronj2005.0106. 